\title{
Arqueologia colaborativa não é o fim
}

\author{
Chip Colwell* \\ Rafael de Almeida Lopes**
}

COLWELL, C.; LOPES, R. A. Arqueologia colaborativa não é o fim. R. Museu Arq. Etn. 34: 41-47, 2020.

Resumo: Há mais de um século a arqueologia científica estava presa nas teias do colonialismo. Ao redor do globo, nações extraiam recursos culturais de locais distantes - mais frequentemente em comunidades indígenas - para tecer histórias, construir museus e arrecadar prestígio e poder para acadêmicos e suas instituições. Nos anos 1970, ativistas indígenas e seus aliados começaram a criticar esse modelo e a propor alternativas que empoderavam comunidades locais a controlar seu próprio patrimônio. Uma das ideias mais importantes desse movimento foi a de arqueologia colaborativa, que defende um compartilhamento equiparado do passado entre cientistas e membros das comunidades. A colaboração gerou novas possibilidades radicais para a arqueologia. Entretanto, chegamos a um momento importante, no qual temos que considerar como a colaboração corre o risco de reforçar estruturas de poder colonialistas, quando é praticada como um meio e não como um fim. Colaboração em arqueologia não é uma solução para o colonialismo, mas uma ferramenta que comunidades e acadêmicos podem usar para concretizar a busca da disciplina por um futuro pós-colonial.

Palavras-chave: Colaboração; Igualdade; Método científico.

\section{Introdução}

$\mathrm{O}$

Estados Unidos nasceram em 1776. Quase que imediatamente após essa criação havia um desejo em puxar a fronteira do país à Oeste. Homens, mulheres e crianças juntavam seus pertences e viajavam para um futuro desconhecido. Enquanto derrubavam florestas, construíam estradas e casas e abriam terras para fazendas e pastos esses grupos fronteiriços depararam com imensos montículos de terra.

* Curador Sênior de Antropologia, Denver Museum of Nature \& Science. <chip.colwell@dmns.org>

** Tradução, doutorando do Programa de Pós-Graduação em Arqueologia da Universidade de São Paulo (PPAEQ-USSP). <rc.lopes4@gmail.com>
Pontuando a paisagem como um tecido de bolinhas, os montículos eram claramente artificiais. Eles se erguiam em planícies do Leste da América do Norte e mantinham uma clara simetria. Dentro e ao redor deles foram encontrados artefatos - instrumentos de pedra, cerâmica, conchas, ossos. A maioria das pessoas imaginava que há muito tempo uma grande e poderosa civilização construiu seu império ao redor desses montículos. Alguém havia feito esses monumentos há tempos. Mas quem?

Historiadores e fazendeiros ofereceram muitas hipóteses. Talvez tenha sido a Tribo Perdida dos Israelitas; ou talvez, os antigos egípcios, antigos gregos perdidos, fenícios, tártaros, cartagineses, galeses, nórdicos, celtas... entre outros. 
Alguns, como o segundo presidente estadunidense Thomas Jefferson, ficaram tão curiosos com esses montículos que os escavaram. Jefferson sugeriu que os ancestrais dos povos indígenas da América do Norte construíram esses montículos, e até levantou a hipótese de que esses povos poderiam ter vindo da Ásia (Jefferson 1787). Entretanto, uma opinião muito mais comum foi aquela compartilhada por um texano famoso chamado Sam Houston.

Eu encontrei frequentemente fortificações de terra que evidenciam a existência de um povo que chegou a um estado relativamente alto da civilização" ele disse. "Há um mistério aí. Mas não se pode duvidar de sua existência, e nada indica que os índios dos nossos dias são remanescentes dessa civilização (Hinsley 1996: 180).

O "mito dos moundbuilders", como a questão e a controvérsia vieram a ser chamadas, não foi dissolvido até 1894, quando um arqueólogo chamado Cyrus Thomas provou definitivamente que indígenas construíram todos os montículos de terra antigos da América do Norte (Silverberg 1968). A questão-chave, talvez, não é porque demorou tanto para se resolver a polêmica (afinal de contas, Thomas Jefferson já havia feito isso em 1787), mas porque o mito persistiu por tanto tempo.

O mito que ruínas foram construídas por qualquer um menos os povos indígenas serviu à lógica do colonialismo. A linha de raciocínio era mais ou menos assim: "sim, alguém viveu aqui há muito tempo, provando que esse lugar é capaz de conter uma grande civilização. Mas os povos indígenas são muito primitivos para ter construído esses monumentos antigos; eles são novatos, como nós. Portanto, essa terra é aberta e livre para nós colonos para redescobrir seu potencial e recapturar sua glória”.

Essa história não é única na América do Norte. É, essencialmente, a história de todo continente que foi sujeitado ao colonialismo. Colonos de todos os cantos precisam dar sentido às suas novas casas, sabendo, implícita ou explicitamente, que alguém esteve lá antes deles.
A arqueologia, então, não é independente de questões políticas e de poder ao abordar essas questões de origem e de pertencimento. Do uso da arqueologia pelos nazistas ao uso da arqueologia na guerra Israel-Palestina; ao uso de Stonehenge por New Agers; ao uso da arqueologia na Índia por nacionalistas Hindu; à destruição iconoclasta dos Budas de Bamiyan a arqueologia como história e patrimônio está enveredada nos conflitos das sociedades para imaginar e para articular a si mesmas (Abu el-Haj 2001; Arnold 1990; Bender 1998; Bernbeck \& Pollock 1996; Colwell 2003).

Eu começo o presente artigo com essa história pois temos que reconhecer de início que a arqueologia é uma empreitada política. Em vez de rejeitar as políticas da arqueologia, arqueólogos precisam se debruçar sobre qual política ela deve servir. Eu proponho que a arqueologia deve servir às políticas da democracia e da inclusão. E mesmo que o campo de fato tenha feito grande progresso nessa direção, eu pergunto se alcançou realmente novas soluções ou se, ao contrário disso, está apenas reforçando velhas estruturas de poder.

\section{Do colonialismo a colaboração}

O historiador da arqueologia Bruce Trigger (1984) sugeriu que o campo da arqueologia moderna nasceu de três impulsos.

Em primeiro lugar, das arqueologias nacionalistas, que incluem atividades voltadas ao fortalecimento de sentimentos patrióticos; à glorificação do passado nacional e ao encorajamento da resistência a estados inimigos, que serão usados depois para encorajar um espírito de unidade e de cooperação em estados industrializados. Em segundo, das arqueologias imperialistas, que são uma forma de hegemonia, sob a qual essas nações exercem forte influência cultural, política e econômica sobre seus vizinhos. E em terceiro, das arqueologias colonialistas que se desenvolveram em lugares nos quais as populações nativas foram inteiramente substituídas ou dominadas por assentamentos europeus, ou nos quais 
os europeus se mantiveram dominantes politicamente e economicamente por um longo período.

É nessa terceira forma em que se iniciou a arqueologia em lugares como o Brasil e os Estados Unidos. Começando no século XIX, as arqueologias colonialistas iniciais argumentavam que povos indigenas eram inerentemente atrasados e incapazes de adotar um "estilo de vida civilizado". Havia uma relutância generalizada em reconhecer os povos em seus lugares através dos tempos. Toda sociedade "avançada” era considerada como fruto de raças "perdidas", desconexas dos povos indígenas vivos. Qualquer mudança registrada no passado era normalmente enquadrada como uma substituição cultural - povos indígenas atuais violentamente destruíram os povos do passado, o que, por sua vez, poderia justificar a violência contra os povos indígenas atuais. Como explica Trigger (1984: 360):

Enquanto os colonizadores tinham todas as razões para glorificar seu próprio passado, eles não tinham razão nenhuma para louvar o passado dos povos que estavam subjugando e dominando. Decerto, por enfatizar o primitivismo e a falta de feitos desses povos, eles buscavam justificar seus maus-tratos para com eles.

Os ecos desse enquadramento colonialista ainda podem ser ouvidos e sentidos hoje. Por exemplo, estão presentes nos populares livros de Jared Diamond, como Colapso e Armas, Germes e Aço, que dependem fortemente de uma noção do indígena "desaparecido" (Wilcox 2010).

Outro exemplo é a popularidade dos "alienígenas antigos" em programas de TV e livros, como explicação do sucesso de povos indígenas do passado. Alienígenas antigos são o mito dos moundbuilders moderno.

Nos Estados Unidos, o debate sobre o que fazer com os restos mortais do antigo ameríndio conhecido como "O Antigo" (The Ancient One) ou "Homem de Kennewick" (Kennewick Man) também deixou essas temáticas claras. Muitos argumentaram, e a corte federal estadunidense concordou que o restos eram "muito velhos" para serem indígenas. Para distanciar a pessoa antiga dos ameríndios, arqueólogos arguiram por meio de reconstruções imaginadas que "O Antigo" pareceria com o ator branco Patrick Stewart. Uma reconstrução subsequente foi modelada a partir dos Ainu do Japão. DNA antigo mostrou que essa pessoa era ancestral de indígenas; mesmo assim os arqueólogos que o estudam ainda não produziram uma reconstrução baseada no fenótipo ameríndio.

A arqueologia colonialista é desafiada há muito tempo. Até no século XIX, documentos provam que povos indígenas se opunham à remoção de seus ancestrais de suas tumbas e do roubo de seus objetos sagrados (Colwell 2010). Entretanto, é só a partir dos movimentos por direitos civis dos anos 1960 - e uma mudança nas políticas públicas, do extermínio para a autodeterminação - que os povos indígenas tiveram poder político suficiente para começar a avançar contra as práticas arqueológicas colonialistas (Deloria Jr. 1969). Mais amplamente, nos anos 1970, acadêmicos nas Ciências Sociais e Humanidades se voltaram a questões sobre a história colonial (Said 1978).

No meio dessa transformação, arqueólogos começaram a prestar mais atenção em como não acadêmicos interagiam com esse campo. Isso nasce inicialmente da percepção que o apoio do público poderia fomentar a pesquisa arqueológica, especialmente nos âmbitos do financiamento público e das leis de patrimônio. Nos anos 1970, a "arqueologia pública" surgiu (McGimsey III 1972). Essa prática nasce explicitamente da indústria de administração de recursos culturais. Como primeiramente conceptualizada, era unidirecional e didática. Na prática, envolvia muitas apresentações, tours e exibições (Potter 1994). Esse trabalho era visto como um acréscimo ao status quo, envolvendo trabalho ao fim do projeto para "mostrar" o que os arqueólogos tinham aprendido (Pryor 1989).

Ao fim dos anos 1990, alguns acadêmicos começaram a questionar se arqueólogos precisariam se engajar com as comunidades de forma mais profunda e significativa particularmente com as comunidades que compartilhavam o domínio de recursos 
arqueológicos ou que descendiam dos povos sendo estudados (Funari 2001; Marshall 2002; Shackel \& Chambers 2004). A arqueologia comunitária surgiu da arqueologia pública, mas virou mais multivocal e engajada. Virou também participativa: esperava-se que membros do público fossem participantes ativos. Essa mudança era motivada por críticas a exclusividade da autoridade arqueológica e uma percepção de que o patrimônio é compartilhado (Schmidt 2014). A arqueologia comunitária desafiou o status quo: o trabalho atravessaria inteiramente os projetos e buscaria reescrever a tarefa arqueológica (Smith \& Waterton 2009).

No começo dos anos 2000, enquanto a arqueologia comunitária estava se estabelecendo, arqueólogos, nos quais me incluo, sugeriram a possibilidade de uma arqueologia colaborativa (Colwell 2008 \& Ferguson; Silliman 2008). Esse projeto compartilhava dos objetivos transformacionais, métodos inovadores e interpretações multivocais da arqueologia comunitária, mas questionava que "comunidade" implicava (intencionalmente ou não) um foco em delinear posicionamentos, geografias e pertencimentos a grupos. O foco da colaboração é no ato e no processo de trabalhar juntos - as formas com as quais arqueólogos engajam não arqueólogos por meio de práticas guiadas eticamente.

De forma simples: colaboração é mais método que teoria - mais um meio que um fim.

A partir de influências de campos como o collaborative inquiry, meus colegas e eu sugerimos como a colaboração podia se desdobrar por meio do contínuo processo de trabalho conjunto com comunidades de descendentes. Para isso, um processo de quatro passos envolveria (1) formar um grupo de copesquisadores; (2) criar condições de coaprendizado; (3) atuar nos questionamentos; e (4) construir significado ao construir conhecimento em grupo (Bray et al. 2000). O conhecimento recém-construído, então, levaria à formação de um novo grupo de copesquisadores ou circularia por novos conjuntos de perguntas.
Os princípios dessa nova abordagem incluiriam:

- Participação e democracia.

- Pesquisa não sobre as pessoas, mas com as pessoas.

- Reflexividade pode corrigir distorções, raciocínios, percepções e atitudes.

- Entendimentos díspares podem transformar as próprias experiências e os modos de ser.

- O pesquisador não está fora da experiência de pesquisa, mas é uma parte dela.

- E suas características seriam:

- Produz conhecimento interdisciplinar.

- Conecta passado ao presente.

- Abriga públicos diversos como stakeholders.

- Dá voz a comunidades de descendentes.

- Almeja ser aplicada e orientada a ação.

Como Carolyn Fluehr-Lobban (2003: 242) escreveu que a colaboração em antropologia é uma tarefa de autoria conjunta e conjuntamente direcionada na qual "o envolvimento comunitário no processo de pesquisa se torna condição para seu sucesso - não simplesmente um subproduto fortuito de trabalhar com comunidades".

Uma característica importante da arqueologia colaborativa é que ela não abdica da ciência, mas a acolhe. Como Alison Wylie (2008) argumentou, convincentemente, para a ciência florescer, ela precisa se guardar constantemente da "cegueira epistêmica" e da "insularidade epistêmica".

Em outras palavras, precisa ser contra a criação de baluartes intelectuais que excluem outras formas de saber, outras formas de conhecimento. $\mathrm{O}$ crescimento da ciência requer novas ideias e uma inclinação para desafiar convicções aceitas (Kuhn 1996). Importantemente, o tipo de inclusão intelectual que está no cerne da colaboração é, portanto, não um repúdio aos princípios científicos, mas, ao contrário, um aspecto vital deles. Permitir autoridades arqueológicas descartar maneiras alternativas de ver o mundo de forma casual ou discriminatória é um modo de "injustiça epistêmica" (Fricker 2007). 


\section{Apesar disso, as raízes do colonialismo são profundas}

Muitos já escreveram sobre os insights e engajamentos éticos proporcionados pela arqueologia colaborativa e suas primas intelectuais, como as arqueologias indígenas (Acabado, Martin \& Datar 2017; Cipolla, Quinn \& Levy 2019; Colwell 2016; McAnany \& Rowe 2015; Mrozowski 2017; Nicholas 2012; Welch, Lepofsky \& Washington 2011; Wylie 2015). E, mesmo assim, apesar desses novos métodos e ideias, as raízes do colonialismo persistem.

O antropólogo Robin Boast advertiu vigorosamente contra a complacência. Ele argumenta que nossa nova era de engajamento colaborativo pode não ser nada pós-colonial, mas sim um modo neocolonial em que as práticas de museus continuam profundamente extrativas e desiguais (Boast 2011). Ele defende sua posição mostrando como relações de poder profundamente assimétricas persistem em lugares como museus, onde grupos culturais dominantes "negociam" espaços que eles, na realidade, controlam. Museus, escreve Boast, se adaptaram às "sobras" do colonialismo, ao invés de transcendê-las.

A arqueologia corre o mesmo risco. Apesar de mudanças em alguns lugares por alguns acadêmicos, de forma geral, arqueólogos mantiveram seu poder em vez de renunciá-lo. Arqueólogos fazem isso ao manter controle sobre dinheiro e recursos. Eles também fazem isso por exclusão: pouquíssimos indígenas são arqueólogos profissionais. A pesquisa normalmente avança os objetivos da ciência, mas não as necessidades materiais das comunidades. Recompensas dentro da academia desfavorecem a colaboração profunda: arqueólogos conseguem empregos e louvores por meio de livros e publicações de autoria solo. Arqueólogos frequentemente evitam os assuntos que mais importam às comunidades como direitos à agua e à terra, proteção ambiental, empregos e saúde. Colaboração pode muito frequentemente envolver boas intenções, mas, mesmo assim, criar pouca mudança.

O campo da arqueologia sofre o que Bryony Onciul (2015) chama de "desigualdades naturalizadas”. O conceito quer dizer que desigualdades estruturais estabelecidas pelo colonialismo persistem em projetos e pesquisas arqueológicas, mesmo diante de tentativas de empoderamento comunitário.

\section{Descolonizando a arqueologia}

Essa crítica não sugere que a colaboração não seja importante ou significativa. Ela é. O que precisa acontecer agora é um comprometimento a um engajamento real e com maior profundidade. Colaboração não é pós-colonial. Colaboração é um ato de descolonização.

Como podemos saber se a colaboração da arqueologia simplesmente reinscreve velhas relações de poder ou as transforma? Eu sugiro que podemos medir nosso progresso em três áreas-chave:

1. Economia política: como as comunidades colaboradoras administram seus recursos?

As estratégias estão realinhando arranjos históricos de poder e de dinheiro?

2. Voz: quais vozes direcionam a pesquisa e seus resultados? As estratégias fomentam uma multivocalidade crítica?

3. Benefícios: os benefícios do projeto fluem para quem? As relações são mutuamente enriquecedoras e sustentáveis?

Em conclusão, apesar das possibilidades radicais da arqueologia colaborativa, precisamos sempre estar atentos em como ela pode desafiar ou reafirmar o status quo. Podemos fazer isso ao não tomar como dado que a colaboração seria inerentemente mais ética. Devemos evitar os sonhos de um mundo pós-colonial e abraçar o trabalho permanente de descolonização.

E devemos sempre lembrar do outro sentido de colaborador: aquele que trabalha com o inimigo. Devemos trabalhar constantemente para garantir que as pessoas que escolhem colaborar o estão fazendo para o bem de suas comunidades e de si mesmos, tanto quanto em serviço da ciência.

Colaboração é um meio para igualdade, reciprocidade e justiça. Colaboração não é um fim em si mesmo. 
COLWELL, C.; LOPES, R.A. Collaborative archaeology is not the end. R. Museu Arq. Etn. 34: 41-47, 2020.

Abstract: More than a century ago, scientific archaeology was caught up in the webs of colonialism. Around the globe, nations extracted cultural resources from distant places - especially in Indigenous communities - to construct stories, build museums, and garner prestige and power for academics and the institutions they served. In the 1970s, Indigenous activists and their allies began to challenge this model and propose alternatives that empowered local communities to control their own heritage. One of the most important ideas to arrive out of this movement was that of collaborative archaeology, which argues for an equitable sharing of the past between scientists and community members. Collaboration has opened up radical new possibilities for archaeology. However, we have arrived at a key moment where we must consider how collaboration also risks reinscribing colonialist power structures in modern society when it is practiced as an end instead of a means. Collaboration in archaeology is not a solution to colonialism, but a tool that communities and scholars can use in the field's search for a postcolonial future.

Keywords: Collaboration; Equality; Scientific method.

\section{Referências bibliográficas}

Abu el-Haj, N. 2001. Facts on the ground: archaeological practice and territorial self-fashioning in Israeli society. University of Chicago Press, Chicago.

Acabado, S.; Martin, M.; Datar, F. Ifugao archaeology: collaborative and indigenous archaeology in the Northern Philippines. Advances in Archaeological Practice 5: 1-11.

Arnold, B. 1990. The past as propaganda: totalitarian archaeology in nazi Germany. Antiquity 64: 464-478.

Bender, B. 1998. Stonehenge: making space. Berg Press, Oxford.

Bernbeck, R; Pollock, S. 1996. Ayodhya, archaeology, and identity. Current Anthropology 37: 138-142.

Boast, R. 2011. Neocolonial collaboration: museum as contact zone revisted. Museum Anthropology 34: 56-70.
Bray, J.N. et al. 2000. Collaborative inquiry in practice. Sage, Thousand Oaks.

Cipolla, C.N.; Quinn, J.; Levy, J. 2019. Theory in collaborative indigenous archaeology: insights from Mohegan. American Antiquity 84: 127-142.

Colwell, C. 2003. Dismembering/disremembering the Buddhas: renderings on the internet during the Afghan purge of the past. Journal of Social Archaeology 3: 75-98.

Colwell, C. 2010. Living Histories: Native Americans and Southwestern Archaeology. Altamira Press, Lanham.

Colwell, C.; Ferguson, T.J. 2008. Collaboration in archaeological practice: Engaging descendant communities. Altamira Press, Lanham.

Colwell, C. 2016. Inheriting the past: the making of Arthur C. Parker and Indigenous archaeology University of Arizona Press, Tucson. 
Deloria Jr., V. 1969. Custer died for your sins: an Indian Manifesto. Macmillan, New York.

Fluehr-Lobban, C. 2003. Dialogue for ethically conscious practice. In: Fluehr-Lobban, C. (Ed.). Ethics and the profession of anthropology: dialogue for ethically conscious practice. AltaMira Press, Walnut Creek, 225-246.

Fricker, M. 2007. Epistemic injustice: power and the ethics of knowing. Oxford University Press, Oxford.

Funari, P.P.A. 2001. Public archaeology from a Latin American perspective. Public Archaeology 1: 239-243.

Hinsley, C.M. 1996. Digging for identity: reflections on the cultural background of collecting. American Indian Quarterly 20: 180-196.

Jefferson, T. 1787. Notes on the state of Virginia. John Stockdale, Piccadilly.

Kuhn, T.S. 1996. The structure of scientific revolutions. University of Chicago Press, Chicago.

Marshall, Y. 2002. What is community archaeology? World Archaeology 34: 211-219.

McAnany, P.A.; Rowe, S.M. 2015. Re-visiting the field: collaborative archaeology as a paradigm shift. Journal of Field Archaeology 40: 499-507.

McGimsey III, C.R. 1972. Public archaeology.Seminar Press, New York.

Mrozowski, S.A. 2017. Listening and learning: the benefits of collaborative archaeology. SAA Archaeological Record 17: 28-30.

Nicholas, G. 2012. Collaborative, community-based heritage research, and the IPinCH project. SAA Archaeological Record 12: 30-32.

Onciul, B. 2015. Museums, heritage, and indigenous voice: decolonising engagement. Routledge, New York.

Potter, P.B. 1994. Public archaeology in Annapolis: a critical approach to history in Maryland's "ancient city". Smithsonian Institution Press, Washington.
Pryor, F. 1989. Look what we've found - a case study in public archaeology. Antiquity 63: 51-61.

Said, E.W. 1978. Orientalism. Vintage Books, New York.

Schmidt, P.R. 2014. Rediscovering community archaeology in Africa and reframing its practice. Journal of Community Archaeology \& Heritage 1: 37-55.

Shackel, P.A.; Chambers, E.J. (Eds.). 2004. Places in mind: public archaeology as applied anthropology. Routledge, London.

Silliman, S.W. (Ed.). 2008. Collaborating at the trowel's edge: teaching and learning in indigenous archaeology. University of Arizona Press, Tucson.

Silverberg, R. 1968. Mound builders of ancient America: the archaeology of a myth. New York Graphic Society, Greenwich.

Smith, L.; Waterton, E. 2009. Heritage, communities, and archaeology. Duckworth, London.

Trigger, B.G. 1984. Alternative archaeologies: nationalist, colonialist, imperialist. Man 19: 355-370.

Welch, J.R., Lepofsky, D.; Washington, M. 2011. Assessing collaboration with the Sliammon first nation in a community-based heritage research and stewardship program. Archaeological Review from Cambridge 26: 171-190.

Wilcox, M. 2010. Marketing conquest and the vanishing indian: an indigenous response to Jared Diamond's Guns, germs, and steel and collapse. Journal of Social Archaeology 10: 92-117.

Wylie, A. 2015. A plurality of pluralisms: collaborative practice in archaeology. In: Padovani, F.; Richardson, A.; Tsou, J.Y. (Eds.). Objectivity in science: new perspectives from science and technology studies, Springer, New York, 189-210.

Wylie, A. 2008. Legacies of collaboration: transformative criticism in archaeology. In: Proceedings of American Anthropological Association Conference, 2008, San Francisco. 